\title{
The emergence of Leadership for Learning beliefs among Flemish secondary school leaders
}

Leadership for Learning (LFL) recently emerged as a comprehensive framework integrating aspects of theories thus far applied in school leadership research. LFL provides the principles for practice believed to effectively deal with the increasing complexity and expectations in education. Via semi-structured interviews this paper seeks to deepen our understanding of the leadership practices and beliefs among principals in Flemish secondary education and assess the occurrence of LFL in practice. Due to busy schedules, little time remains for principals to continuously focus on learning and teaching. This issue might be resolved by strengthening learning climates, sharing leadership, and fostering dialogue and a sense of shared accountability.

Keywords: leadership; leadership for learning; leadership development; secondary education secondary school management; principalship

Word count: 8,461 words, excluding the supplementary material in annex

\section{Introduction}

Schools around the world operate in a rapidly changing and demanding environment, causing education to become an increasingly complex affair (Bush \& Glover, 2014). While societal and managerial trends put pressure on education from the outside to meet a wide array of expectations and complaints, educational systems also contend with challenges from within. These two sources of pressure closely intertwine and put a continuing burden on educational professionals. 
Flemish, and by extension Belgian, school leaders are no exception to this rule. This raises pertinent questions. How do school leaders manage? And what kind of leadership is suitable to keep a school operating effectively in these highly demanding times? Over the past three decades, school leadership attracted considerable attention as scientific research topic (Robinson et al., 2008). This article contributes to the theorizing on school leadership from a Flemish practitioners' perspective.

Pressure on education providers increased due to both societal and policy shifts. Large scale immigration flows, for example, added to the diversity of classrooms (Sels et al., 2017). Pressures on education further increased following New Public Management reforms. While principals are allowed more autonomy in leading their schools, the measurable objectives set to hold them accountable entail more administrative burdens as to successfully account for all actions taken (Devos et al., 2018). This bureaucratization might cause dissatisfaction and detachment from the job as principals feel overworked, under pressure from impossible time schedules and an overbearing amount of paperwork (MacBeath et al., 2012).

Schools are furthermore preeminently considered a vehicle for social change and national economic competitiveness by policy-makers and the wider community (Forde, 2011; MacBeath et al., 2012). However, when societal expectations are deferred to education under the guise of educating future generations of citizens, educators are at risk of becoming overwhelmed (MacBeath et al., 2012). Increased demands are rarely met by increased financial resources (Flemish Ministry for Education and Formation, 2017). And whereas organizational innovation could counter - or at least ease - these burdens, Flemish schools still function according to logics and structures in which hierarchy and upward accountability are firmly embedded (Penninckx et al., 2016). Flemish principals not only face external challenges, they are also 
expected to manage contextual problems within the Flemish secondary education system such as the reproduction of social inequality (Lavrijsen et al., 2013) and an imminent shortage of teachers (Moens, 2019).

As pressure on principals is many-sided, even the highest performing principals in Flanders show signs of burn-out and report on prolonged periods of stress throughout a school year (Devos et al., 2018). In addition, principal turnover is high. In 2018, 34\% of Flemish secondary schools started the school year with another principal (AGODI, 2019). As a result, a great deal of expertise is lost and continuity and long-term vision within schools are hindered.

Given these challenges, Flemish secondary school leaders are an intriguing case for further research. Firstly because a predominantly Anglo-American theorizing on school leadership is turning more international with efforts such as the Carpe Vitam Leadership for Learning Project (MacBeath \& Dempster, 2009). This article aims to contribute to this internationalization. Secondly, Flanders offers a unique case for school leadership research as government interference remains limited. Not only is education in Belgium a devolved competence exercised by three community governments (i.e. the Flemish, French and German speaking community), a substantive discretionary power resides with the organizers of Flemish education. The Flemish government (GO!), the Flemish provinces (POV), the Flemish cities and municipalities (OVSG) and catholic private actors (KOV) all organize education. Whereas these educational networks have to attain the targets set by the Flemish legislator, they remain free to determine what is expected of the principals within their network and organize their professional development accordingly. Since no overarching Flemish competence framework for school leadership is in place, this article tries to map its current state. 


\section{Literature}

This section provides an overview of leadership theories dominant in the field of education (Daniëls et al., 2019): transformational leadership, instructional leadership, distributed leadership and, most recently, leadership for learning. The overview will guide the analysis section in distinguishing the leadership styles and conceptions prevalent among Flemish secondary school leaders. It will also allow us to relate these styles and conceptions to contemporary expectations and prescriptions for effective schooling in school leadership literature.

\section{Transformational leadership}

Central to transformational leadership theories are the attitudes, behaviors, capacities, engagement and motivation of coworkers (Bass, 1995; Leithwood et al., 1999; Seltzer \& Bass, 1990). It is important for leaders to foster a feeling of involvement and engagement among staff as higher levels of staff members' commitment to the organization's mission and objectives create greater willingness to contribute thereto. Transformational leaders do so by formulating a clear, ambitious and invigorating mission with corresponding objectives. In its design process stakeholders are heard and their opinions, values, aspirations and complaints are taken into account. The mission therefore forms a supported and shared agreement (Marks \& Printy, 2003). Staff members are also transformed to higher levels of performance, motivation and commitment through 'individualized consideration' and 'intellectual stimulation' by their superior (Seltzer \& Bass, 1990). He or she is a people manager who lends an ear to coworkers' aspirations, concerns and/or problems, advising and coaching them along the way; someone who addresses coworkers' capacities and talents and grants them the liberty and opportunities to develop themselves

personally as well as professionally. Able staff members, in turn, are more likely to make a 
substantial contribution to the realization of school objectives (Leithwood \& Jantzi, 2000).

Finally, a transformational leader models the behavior he wants to see in coworkers. Bass (1995) termed this 'idealized influence'.

\section{Instructional leadership}

Unlike transformational leadership, instructional leadership tries to grasp the complexity and specificity of leadership in an educational context (Bush \& Glover, 2014) by explicitly linking a principal's actions to school and student outcomes (Hallinger, 2003; Hallinger \& Murphy, 1985; Robinson et al., 2008).

According to Hallinger and Murphy (1985), in defining the school mission, managing the instructional program and promoting the school learning climate, principals undertake all necessary actions to address teaching and learning and thus engage in effective schooling. Hallinger (2003) goes on to define ten specific leadership functions within these three action categories. Defining the school mission in this way entails the formulation and communication of school objectives. In managing the instructional program, principals are expected to coordinate the curriculum, supervise and evaluate instruction and monitor student progress. Finally, a principal promotes a strong and vibrant learning climate by protecting instructional time, stimulating teachers, promoting professional development and maintaining a high visibility.

Over the years, the idea of instructional leadership was, however, a frequent subject to criticism. First, principals are considered lonesome heroes in charge of teaching and students' and coworkers' learning. They are at the very center of expertise and act as the driving forces in school decision-making (Hallinger, 2003). In contrast, teachers are merely regarded as a school leaders' obedient followers (Marks \& Printy, 2003). Principals should, instead, be considered one 
of many leaders as multiple professionals within a school need to combine strengths for effective schooling (Townsend et al., 2013). Additionally, Leithwood et al. (2006) and Day et al. (2008) found school leaders to exert most influence on teaching and learning through indirect means (e.g., raising staff motivation and commitment) rather than direct ones (e.g., weighing on instruction through personal expertise and experience). Second, instructional leadership is too concerned with teaching and learning, and, as a consequence, neglects the administrative, legal and financial aspects of running a school. Curiously, it is these aspects of management that gained importance (MacBeath \& Dempster, 2009). Third, as a framework, instructional leadership provides too little guidance on how to be a successful principal as it focusses predominantly on what school leaders should do rather than how they should be doing it (Bush \& Glover, 2014).

\section{Distributed leadership}

Distributed leadership models dismissed previous models' one-sided view on school leaders as lonesome heroes on top of their organization (Bush \& Glover, 2003) as this premise would require a principal to possess an impossible amount of knowhow and skill to cope with today's expectations (Bush, 2018; Bush \& Glover, 2012). Instead, leadership can be adopted by multiple individuals or teams within a school (Harris \& DeFlaminis, 2016; Leithwood, Mascall, et al., 2008; Spillane et al., 2015). Depending on the context, size, complexity and scope of a task, various individuals or teams can be involved at different times and to varying degrees (Torrance, 2013). 
In examining the distribution of leadership within a school, one can look at how these functions are dispersed over formal positions within the organization (e.g., the principal, assistant-principal(s), grade coordinators, student counselors etc.) as the holders of these functions were officially assigned and trusted leadership responsibilities. Achieving shared leadership assumes experienced teachers willing to take responsibility, engage in the realization of school objectives, let their voices be heard and commit to the collective building of knowledge and understanding (Frost, 2008). Yet, next to a personal choice it also implies an organizational state of affairs. It presupposes a culture of trust and collaboration, strong and purposeful professional development opportunities and a principal that organizes, supports and coordinates teacher leadership through clear and transparent structures in alignment with a shared vision of where the school needs to go (Leithwood, Mascall, et al., 2008; Muijs \& Harris, 2006).

The concept of distributed leadership is nevertheless not restricted to those in formal positions. As leadership can be exercised informally by every single school member (Muijs \& Harris, 2006; York-Barr \& Duke, 2004), distributed leadership is more than solely the sum of distributed responsibilities. An important feature is also clear communication and solid interaction between leaders (Devos et al., 2014), next to allowing broad and regular staff participation and consultation (Day et al., 2008; Leithwood et al., 2006).

MacBeath et al. (2018) notice, however, how distributed leadership often implies a continuation of a leader-centrist view. A positional leader is thereby needed to establish, empower and maintain collaboration and shared responsibility-taking. (S)he sets out the gridlines and provides the resources via which teachers are, individually or collectively, allowed to use their expertise and given responsibility yet seldom autonomy (Park \& Datnow, 2009). In order to break with an hierarchal and top-down approach, several scholars incite on combining multiple 
perspectives on leadership (e.g., transformational, instructional and distributed) in a new and comprehensive theory (e.g., Marks \& Printy, 2003; Robinson et al., 2008; Townsend et al., 2013).

\section{Leadership for Learning (LFL)}

The comprehensive theories that emerged are most frequently denoted with the term 'leadership for learning' (LFL) (Bush \& Glover, 2014). A concept that, in spite of its variety in interpretations (MacBeath et al., 2018), shares a common base through which features of all aforementioned leadership theories are integrated (Daniëls et al., 2019). This paper discusses the practical LFL interpretation provided by the seven country Carpe Vitam study (MacBeath \& Dempster, 2009) and the normative LFL interpretation by the effective school studies (Murphy et al., 2007).

The Carpe Vitam study distillated five principles for an LFL practice to guide educational professional through to the myriad of expectations (MacBeath et al., 2018). The first principle stresses the importance of maintaining a consistent and explicit focus on learning (MacBeath et al., 2009). Everyone within the school should be allowed a maximum of opportunities to learn and to take responsibility for the learning of others. Administrative, financial and logistical aspects of schooling are of secondary importance as they serve qualitative teaching (Murphy et al., 2007). The second principle deems the creation of a strong, trusting and vibrant learning climate indispensable for school performance and improvement (MacBeath et al., 2009; Marsh, 2015). In such a climate resources are set aside to optimize the physical, social and emotional learning conditions of students and teachers alike. It allows for frequent reflection and debate on learning, encourages experimenting, recognizes the learning opportunities in failure and 
acknowledges success (MacBeath et al., 2018).

The third principle illustrates the added value of a qualitative and continuous dialogue about both leadership and learning within the school. Collegial inquiry and disciplined dialogue allow for new perspectives to be explored, and offers opportunities to challenge existing beliefs, and incites to action (MacBeath et al., 2018).

The fourth principle views educational leadership as a collaborative process of shared responsibility (Hallinger \& Heck, 2010; MacBeath et al., 2018; Marsh, 2015). Supportive structures for teacher participation and collaboration are in place for schools to make the conversion to communities for learning (MacBeath et al., 2009). Communities in which the experience and expertise of staff, students and parents are drawn upon as resources as they are encouraged to take the lead in learning (Schelfhout, 2017).

Finally, as a fifth principle, a shared sense of accountability allows schools to tell its own story amidst rising, or even conflicting, expectations (MacBeath \& Dempster, 2009). To this end, the school can fall back on a strong internal support for its mission and core values. The school, moreover, does not shy away from recasting national policies in accordance with those values if needs be. However, decisions are firmly based on evidence and take into account considerations of sustainability, succession and legacy (MacBeath et al., 2018).

Whereas LFL as defined in the Carpe Vitam study opposes an individual focus on leadership, Murphy et al. (2007) explicitly looked into the leadership practices of the highest performing school leaders in the United States. They delineate an LFL-framework composing of eight dimensions, each further defined in a number of operational actions effective school leaders undertake on a daily basis. These eight dimensions are: (1) vision for learning, (2) instructional 
program, (3) curricular program, (4) assessment program, (5) communities of learning, (6) resource acquisition and use, (7) organizational culture and (8) social advocacy. The Carpe Vitam project, on the contrary, deems leadership a purposeful act that can emanate from each individual within the school. A leadership that improves learning is therefore found in the flow of practice. By restricting the focus to one positional leader's set of practices, a theory is bound to remain partial and limited (MacBeath et al., 2018). 


\section{Research questions}

Given the current state of research on school leadership, this study addresses to the following research question:

- What is the current state of school leadership in Flemish secondary education?

a) Which tasks do Flemish secondary school leaders perform weakly? Why precisely these $\operatorname{task}(\mathrm{s})$ ?

b) How does Flemish school leadership align with recent beliefs of successful school leadership, thus combining different leadership modes?

c) How well do Flemish school leaders measure against LFL's five principles for a contemporary and resilient leadership practice?

In answering these questions, this article aims to contribute to the internationally growing literature on LFL as a means to cope with the myriad of challenges in education. The answers will help the reader in identifying what is already happening LFL-wise in Flemish secondary education and which LFL principles require closer attention. 


\section{Data and Methods}

We chose a qualitative approach to answer our research questions. We conducted 19 semistructured in-depth interviews with Flemish principals who detailed their leadership practices and views on effective leadership in Flemish secondary education. They described:

- the tasks requiring most of their attention during a working week;

- the attitudes and virtues, knowledge and skills an ideal principal should possess or behaviors (s)he should display in order to be successful in the job of school leader.

Additionally, three innovation coaches reported on the same elements based on their experience in working with secondary school leaders. They were added to enrich our data as they provided insights from a different angle. All principals and innovation coaches were selected via purposeful snowball-sampling. From every educational network, the pedagogical head counselor was contacted and asked to refer to either the novice or experienced principals within their network who held strong opinions on school leadership. While experience and outspokenness functioned as the main criteria for selection, secondary criteria (i.e. gender, location and school size) served to filter the references we received. This helped to arrive at a balanced sample. Eventually nineteen principals agreed to an interview. Table 1 provides an overview of respondents' characteristics compared to the overall Flemish percentages.

[Insert table 1]

We conducted all interviews between November 2017 and January 2018. An interview took 46 minutes on average, totaling 16.8 hours of audiotaped interview data. For convenience's sake they were held at the interviewees' schools or offices. Each interview was transcribed verbatim 
and analyzed via NVivo.

This paper takes a theory-driven approach on coding. In doing so, it uses the descriptions within the literature section as a starting point for labeling and counting. Hence, to answer the first sub question, the eight dimensions of the LFL framework by Murphy et al. (2007) functioned as a priori codes for mapping the activities school leaders undertake weakly. For a full description of elements in this framework, the reader is referred to the original article. Table 2 provides the reader with an overview of references to each of the eight categories. It furthermore shows how often reference was made to an element that did not properly fit the effective school studies' categorization. For this reason a ninth and new category was added.

This article administered the same procedure to answer the second and third sub question. All references, direct or indirect, to 'vision building', 'intellectual stimulation', 'individual consideration' and 'idealized influence' were gathered under a transformational leadership denominator. Looking at instructional leadership, we considered all references to 'defining the school's vision and goals'; 'managing the instructional program' and 'promoting the school's learning climate'. For distributed leadership we considered everything that could be linked to (1) delegation and formal dispersion of responsibilities, (2) broad and broadening participation (e.g., allowing co-workers to participate in policy and decision-making, and consulting them regularly via clear and transparent structures), (3) facilitation of cooperation among coworkers, (4) building and maintain a suitable culture for distributed leadership (e.g., a culture that allows autonomy, breaths openness and trust and encourages responsibility-taking) and (5) professional development (as a prerequisite to take on responsibility within the school). Lastly, all references that aligned with the principles of (1) maintaining a focus on learning, (2) creating conditions favorable to learning, (3) creating and engaging oneself in a dialogue about leadership and 
learning, (4) sharing leadership and (5) sharing accountability, were grouped under an LFL denominator. However, this time, coding happened more extensively as not only references that logically aligned with the five principles were coded but also those that described a complete opposite scene or casted doubt thereon.

When labeling leadership, we considered both facts (e.g., descriptions of situations as they currently are) and aspirations (e.g., descriptions of situations as principals would want or believe them to be in the future). Finally, references that connected to multiple theories (e.g., building a school's vision might be coded at 'instructional leadership' just as well as 'transformational leadership'), were coded under all possible nodes it aligned with insofar previous wording could not unambiguously connect it to one category in particular. Tables 3 and 4 provide the reader with an overview of the a priori codes and times they got mentioned throughout the interviews. Exemplary quotes are to be found in annex. 


\section{Results}

The result section starts by focusing on the tasks and activities Flemish secondary school leaders perform weakly. Next, it describes and discusses the prevalent school leadership style(s) among respondents. Finally, it relates respondents' descriptions of both their daily activities and leadership beliefs and aspiration to LFL as described by the Carpe Vitam project.

\section{A week in the life of a Flemish secondary school leader}

When questioned about a week in their professional lives, interviewees described a rich diversity of activities and actions they undertake. 109 out of 139 of those could be fitted in Murphy et al.'s (2007) activity framework as shown in table 2.

[[Insert table 2]

Table 2 also shows how the remaining 30 references were grouped in a separate category labeled ‘Administering and running an organization'. Included in this category were (1) interpersonal relations and personnel welfare (e.g., listening to small frustrations and concerns indirectly or unrelated to the professional sphere), (2) preparing and following-up on large projects indirectly related to schooling (e.g., school mergers, redevelopment projects and construction works), (3) organizing, planning and dispensing relevant information (e.g., answering e-mails and phone calls, following up on certain progress whilst keeping an overview, informing colleagues of new plans and corresponding timeframes) and (4) administration and IT coordination (e.g., the most operational of tasks otherwise assigned to a secretarial office such as keeping guard at the 
playground over lunchtime, taking student absences, etc.).

Three findings emerged when scanning through the references in more detail. First, within all activity categories, principals are often occupied with the most practical of activities residing under each denominator. For example, instead of devising a long-term and ambitious financial plan for the school via the acquisition of additional external funds, school leaders have to finalize tax declarations. They also contend with what they frequently call 'ad hoc problems' or 'putting out fires' (e.g., arranging replacements for ill coworkers, censuring students or resolving interpersonal conflicts between personnel and/or students). In several cases it appears that exactly these small problems and corresponding ad hoc solutions keep them from building an ambitious long-term vision for the school and implementing and stewarding this vision. The following quote serves to illustrate this point:

Due to all small interpersonal conflicts I constantly have to deal with, I actually do not find enough time to work on the things I really would like to work on: outlining a vision and a strategy and finishing plans (Respondent 8 - Female -4 years of experience).

14 out of 22 respondents made clear they - or the principals the innovation coaches work with lack time to maintain a focus on teaching and learning. Hence, school policy making is often referred to as work happening during weekends or holidays:

What I often notice is principals working on very operational things ranging from teaching schedules that need to be drawn up to dealing with students that need to be censured [...]. That 
requires a lot of time, causing them - as so to say - to do the real part of their jobs, thinking about the school's future, after school time (Innovation coach 1 - Male -4 years of coaching experience).

Building on the first finding, this article found in the second place that with only 'Resource acquisition and use' the framework provides too little administratively oriented elements to completely describe all aspects of a Flemish principal's job. One type of activity clearly goes unmentioned: stewarding the administration and the organization as a whole as this not always entails activities directly connected to the school's mission, vision nor strategic or operational objectives but rather mere organizational procedures and accountability. This finding can be linked to a prominent point of critique on the framework. That way, Townsend et al. (2013) argue correctly that LFL as portrayed by Murphy et al. (2007) merely recycles instructional leadership concepts and still pays too little attention to the managerial aspects of a principal's job. This also becomes apparent when principals and innovation coaches talk about the instruction provided at (their) schools. They rarely differentiate between instruction, curriculum and evaluation but tend to regard these as a complex as too little time remains to detangle all three.

In $99 \%$ of the time, I am managing by which I mean organizing the school, directing personnel, solving problems, taking ad hoc decisions ... In fact, I just have to sit down and problems wander into my office. I think that is one of the problems: I became a principal to make school. Yet, if you look at what I spend my time on, that is purely management (Respondent 19 - Male - 12 years of experience). 
A final and third finding shows that while the activity framework pays a lot of attention to communication with a school's most prominent stakeholders (i.e., its teachers), it leaves little room for talking about personal and interpersonal matters and relating to co-workers (e.g., by offering a listening ear and/or an opportunity to simply ventilate frustration). Yet, 5 of the 19 principals report on this kind of communication happening daily.

As principal responsible for personnel, I was almost non-stop occupied with people. I kept an open-door policy meaning people were constantly about for small and big issues. But, that was very important for [their] well-being. When I left - in looking back at the comments I received back then - that is what they appreciated enormously: "We could come in and you would free up time for us even though we knew you were very busy". [...] (Respondent 14 - Female -5 years of experience).

It thus seem that by incorporating personnel management in the instructional program category, the framework keeps its interpretation narrow and limited to hiring, allocating, facilitating and evaluating staff. Consequently, personnel well-being and time spent on interpersonal affairs remain overlooked despite Leithwood, Harris, et al. (2008) underlining the importance of emotional understanding in successful leadership. Emotional understanding and safety are moreover fundamental to LFL's principles for practice. 


\section{Connecting Flemish practice to recent beliefs of successful school leadership}

How then can we describe the leadership Flemish principals display and deem effective?

Throughout the interviews, Flemish principals most often mentioned transformational leadership elements as out of 21 unique interviews, 64 references were coded. Distributed leadership was mentioned 44 times over 18 interviews, whereas elements of instructional leadership were only mentioned 26 times over 16 interviews. Table 3 provides a detailed overview of references per sub category of each leadership framework.

\section{[Insert table 3]}

Considering prior findings about busy work schedules and managing ad hoc administrative affairs, the limited instructional and substantial transformational leadership references are hardly surprising. Here, however, this paper wishes to draw specific attention to distributed leadership and its sub categories. A considerable amount of respondents emphasized the importance of an adequate leadership distribution and an accompanying supportive culture for effective schooling. Even though they were asked about effective leadership in education on an individual or microlevel (i.e. personal values, behavior, knowledge and skills), 12 out of 22 respondents spontaneously added things that, in their opinion, constitute effective school leadership on a structural or macro-level (i.e. organizational structures, procedures and/or culture). All of these related to distributed leadership. These 10 principals and 2 innovation coaches indicated that effective leadership in reality implies something more than simply individual competences or behavior as effective leadership needs all wheels of school to function optimally. In their opinion, 
effective leadership requires collaboration and sound communication between leaders within the school; the maintenance of a school culture characterized by openness, a willingness to share didactical material and meaningful experiences, a profound trust to experiment and take responsibility as a teacher in teacher teams; designing clear and logic structures for coworkers to move in; allowing a voice in decision making and finally granting coworkers opportunities to be co-creative and develop themselves professionally and following-up on these development efforts for the better of the whole school. As one respondent puts it:

A very important element for me is doing things together at this school. We collectively discuss things in which my trust in every single colleague is $100 \%$. And in which I will never call someone to account. Never. Minutes or lessen preparations, I do not want to see anything of the kind. I think this is a kind of trap a lot of [principals] fall into: having a control mechanism. Quit those things because you are making it hard on yourself and you deprive people of their creativity (Respondent 16 - Male - 10 years of experience).

When looking at what has been said about distributed leadership more in-depth, $41 \%$ of references contained allusions to a formal delegation of responsibilities (e.g., a dispersion of tasks that can be traced back within a school's organizational structure). Furthermore, the degree of formal distribution, varied among cases. The following quotes make this variation apparent:

At our school, we have four members on the board of directors. We try to divide tasks between all four in accordance with each's training, personality and capacities (Respondent 17 - Female - 19 years of experience). 
I have a lot of deliberative bodies in my school. I divided the school in four large groups. Each group comprising of eight classes. A coordinator is head of those eight classes and maintains those in cooperation with all form masters. For me this is very useful because they are my contact persons via which I stay up to date with everything happening in class. I often just let things happen. If needs be, I am called in [to deal] with pupils and parents (Respondent 16 - Male - 10 years of experience).

Both these quotes specify a clear and formal way of organizing responsibilities within a school. Yet, while the first example sticks to an hierarchical approach, the second one implies an innovative stance on distributing leadership: a stance that allows informal leadership. The interviews show that exactly this type of distributed leadership happens less often. In some cases, this study was able to discern a discrepancy between what is deemed desirable in terms of effective school leadership (i.e. encouraging informal leadership) and what is actually happening when it comes to a purposeful distribution of leadership responsibilities (i.e. a distribution that maintains a cascade of accountability). Or, as one respondent stated:

[Trusting] is the hardest thing to do: letting go, delegating and, accepting that as long as things run their course you do not hear from them. If there are problems, they know they have to notify me so that I can help search for a solution. I believe that this is our duty [as a principal].

- Meanwhile proclaiming - A lot of things that have to do with administration, I simply delegate. [...] I want to be kept in the loop. That they know. In the end, if a decision has to be made, I am always involved (Respondent 3 - Male - 12 years of experience). 
Finally, respondents easily combined leadership styles as all principals mentioned at least two. Their references were, on average, also fairly dispersed over the different frameworks' categories. A comparison of references based on respondent characteristics (i.e. gender, years of experience, school composition and size) revealed only one notable pattern. The more experienced principals appeared more likely to spontaneously mention effective school leadership elements at a macro-level, with seven out of ten school leaders having at least seven years of professional experience in their current role as principal. Nearly all principals (5 out of 6) that previously held leading positions outside education included effective school leadership elements that transcended themselves. 


\section{Leadership for Learning: an established feature?}

Both the descriptions of daily activity spans and leadership ideals allow an indication of how Flemish secondary principals fare with regard to LFL and its five principles for practice as defined by the Carpe Vitam project (MacBeath \& Dempster, 2009).

[Insert table 4]

Table 4 shows that 142 references were made to one of LFL's five principles, albeit that only 8 out of 19 principal respondents indirectly referred to at least four out of five LFL principles throughout their interview. As a consequence, the five principles do not appear generally established in Flemish secondary education yet. Moreover, the 142 references also include 14 descriptions of scenes that were exactly the opposite of what LFL intended as 9 of the 19 principals made comments of this nature:

On average, I consider my personnel little innovative and enterprising. If I am honest then, over the past 12 years, innovation happened chiefly top-down (Respondent 19 - Male - 12 years of experience).

It is a very lonesome job and there is really no one I trust. [...] I have a few good coworkers and we cooperate well but in the end everyone stabs you in the back (Respondent 9 - Female -15 years of experience). 
Further, 25 of the 142 reference contained a critical reflection. Most often, these reflections confirmed a principal's or innovation coach's believe in the advantage(s) of a certain principle, albeit with a wariness about its feasibility. One innovation coach commented on a shared sense of accountability:

I see that when principals drop out, this does not have to do much with the pressure of work in itself but with the damaged relations they created. By which I mean: in all the hustle, they forced through things in their school. They treaded on toes. They insufficiently enquired about support, therefore, people feel disowned and misunderstood. [...] People drop out because they are weary from hauling a train that is off the tracks (Innovation coach $3-$ Male -4 years of coaching experience).

Finally, the effectuation of LFLs principles appears a long-term awareness process as the 10 school leaders that referred to at least three out of five principles, had 12 years of principal experience on average. In comparison, the remaining school leaders that referred to two or less principles, on average, only had seven years of experience. Of course, even though 103 references aligned with the principles, considerable differences exist:

You need to make sure to follow up on [didactical developments]: current affairs, trends, educational events. I think that is a very important quality you should possess as a principal (Respondent 3 - Male - 12 years of experience). 
A lot of things that go awry in society, people try to solve through education. Then you get ideas from ministers and their cabinets: 'Isn't this something we tackle via schools?' Sometimes that is an order, sometimes not. If it is not an order, you leave it at that (Respondent 4 -Male - 20 years of experience).

Whereas the former sticks to an individual focus on learning, the latter encompasses an attitude that allows multiple individuals within the school to maintain a focus on learning. 


\section{Discussion and future research}

The results demonstrate that even though Flemish secondary school leaders practice a rich diversity of professional activities, the majority of their actions remain very operational.

Organizational and ad hoc interpersonal concerns keep principals from a leadership that improves learning (Marsh, 2015). As vision and mission building are often referred to as work for the weekends or holidays, even less time remains for its actual implementation, let alone regular evaluations. This is problematic as the alignment of a school's vision and mission with school structures and culture is considered a key strategy to improve teaching and learning (Day et al., 2008). Concerns that hamper a consistent focus on teaching and learning are, however, not unique to Flanders (e.g., Sackney \& Mitchell, 2008). After all, a principal also runs an organization. Thinking away organizational and corresponding administrative activities seems utopic (De Man \& Steensels, 2018). School leaders should, however, find themselves in a position that allows them to practice instructional leadership (Hallinger, 2003). How then can we guarantee a sound balance between both sets of responsibilities? An answer is provided by the innovation coaches within the interview design as they articulated a clear need for what they themselves call co-creative leadership:

Respondent 2 (innovation coach): Co-creative leadership is something of which we dare say:

'Today, you cannot do without' [...] I meet few principals that are genuine co-creative leaders. Principals who will tell you: 'I have a vision, I designed a framework and within the limits of that framework I invite co-workers to freely think and work along. 
From their descriptions co-creative leadership arose as a modus operandi that instills a responsibly on educational professionals to take instructional quality into their own hands by transforming schools into genuine learning organizations. Such an organization allows autonomy, facilitates cooperation and encourages experimenting and the sharing of meaningful experiences among staff. Hence, co-creative leadership sets in motion a cycle of gradual teaching improvement. A cycle which school leaders no longer have to uphold by themselves as their teachers can now firstly turn to each other for help and mutual reinforcement. Principals decide on the gridlines for cooperation and enhanced participation and regularly follow up on its progress, which is in line with research on deliberately creating cooperative structures to foster schools as learning communities (Schelfhout, 2017). As a consequence, time can be freed up for principals to work on vision and strategy specifically and maintain a focus on instruction more generally.

MacBeath et al. (2018) observed that even though LFL terminology has been widely adopted over the last decade, interpretations often diverge from Carpe Vitam's core ideas and principles. In spite of its different terminology, the descriptions of co-creative leadership, however, show a striking similarity to LFL's five principles for practice. Given mainly the innovation coaches pointed out the importance of co-creation and co-creative learning in today's education, references to these collaborative ways of working remained scarce among principal respondents.

These findings are in line with other Flemish research (e.g., Hulpia et al., 2009, 2011; Vanblaere \& Devos, 2016) showing co-creative improvement can still be made. Some authors, however, rightfully caution against overly romanticizing this and other notions of distributed leadership. Leadership responsibilities should not be passed on under the guise of distribution as 
teachers might feel tricked into doing more work while top-down decision-making mechanism persist (Harris \& DeFlaminis, 2016). Some patterns of distribution (e.g., the right and legitimate person in the right place) furthermore prove more effective than others in generating desirable organizational outcomes (De Neve \& Devos, 2017; Leithwood, Harris, et al., 2008). A distribution of leadership will, furthermore, not solve all managerial challenges within secondary schools. After all, it does not imply less leadership from a principal but instead puts different demands on his or her interpretation thereof (Leithwood, Mascall, et al., 2008). Administrative burdens (e.g., ranging from drafting a myriad of policy plans to accounts of compliance with hygiene and safety regulations) will also remain high regardless. These burdens require an official rethinking about what is expected, truly necessary and provided as support in exchange (De Man \& Steensels, 2018). Finally, sharing leadership requires a gradual improvement of leadership capacity. A capacity that is not only found within schools but also across and around schools (Harris, 2013). Devos et al. (2018), for example, showed how school boards and the networks' pedagogical counselors can function as true sources of support and advice. Even though these stakeholders remained outside the scope of this study, they should not be forgotten in future research.

Future research should also examine how to professionally develop LFL as a practice in Flemish secondary education. What conditions at school, principal and teacher level need to be fulfilled in order to successfully implement and preserve this type of hybrid leadership? A leadership that emerges in interactive processes as power is exercised with others instead of over others. Among others, an adequate professional development of mainly novice principals can play a considerable role in an early-on establishment of LFL principles. 


\section{Conclusion and limitations}

This article described the current state of Flemish secondary school leadership and linked this reality to contemporary expectations in international school leadership literature. Firstly, this article observed how Flemish secondary principals work very ad hoc and hands-on. Secondly, it found principals to take on - or at least favor - multiple styles of leadership. They meet one of scholars' precepts for successful school leadership: a purposeful integration of different leadership modes. As interviewees indicated that they lack time to maintain a focus on learning, transformational and distributed leadership appeared to align more with their daily leadership than did instructional leadership. Thirdly, this article indicated that LFL's five principles for practice are not always pursued equally as opposing practices persist.

Finally, future research would profit from taking into account some of this study's limitations. As interviews were conducted in the middle of a school year, it is reasonable to assume that the leadership and activity snapshot we acquired might have looked different at any other time during the year. A systematic log of principals' activities over a complete school year would yield more reliable information. This study, furthermore, relied heavily on self-reported and leader-centered data which only renders a partial view on school leadership. A view that is also prone to bias as principals might overstate desirable leadership behavior. In order to acquire a more nuanced image, other actors' perspectives should be examined. Do teachers for example perceive leadership practices in the same way as do their superiors? 


\section{References}

AGODI. (2019). Principal Turnover. Flemish Ministry for Education and Formation - Agency for Educational Services (AGODI).

Bass, B. M. (1995). Transformational leadership redux. Leadership Quarterly, 6(4), 463-478. https://doi.org/https://doi.org/10.1016/1048-9843(95)90021-7

Bush, T. (2018). Preparation and induction for school principals: Global perspectives. Management in Education, 32(2), 66-71. https://doi.org/10.1177/0892020618761805

Bush, T., \& Glover, D. (2003). School Leadership : Concepts and Evidence. National Clollege for School Leadership.

Bush, T., \& Glover, D. (2012). Distributed leadership in action: Leading high-performing leadership teams in English schools. School Leadership and Management, 32(1), 21-36. https://doi.org/10.1080/13632434.2011.642354

Bush, T., \& Glover, D. (2014). School leadership models: What do we know? School Leadership and Management, 34(5), 553-571. https://doi.org/10.1080/13632434.2014.928680

Daniëls, E., Hondeghem, A., \& Dochy, F. (2019). An integrative perspective on leadership and leadership development in an educational setting : A systematic review. Educational Research Review, 27(February), 1-22. https://doi.org/10.1016/j.edurev.2019.02.003

Day, C., Leithwood, K., \& Sammons, P. (2008). What we have learned, what we need to know more about. School Leadership and Management, 28(1), 83-96. https://doi.org/10.1080/13632430701800102

De Man, L., \& Steensels, W. (2018). De directeur vandaag. Perspectieven in schoolleiderschap. (L. De Man \& W. Steensels (eds.)). Politeia. 
De Neve, D., \& Devos, G. (2017). How do professional learning communities aid and hamper professional learning of beginning teachers related to differentiated instruction? Teachers and Teaching: Theory and Practice, 23(3), 262-283.

https://doi.org/10.1080/13540602.2016.1206524

Devos, G., Tuytens, M., \& Hulpia, H. (2014). Teachers' Organizational Commitment: Examining the Mediating Effects of Distributed Leadership. American Journal of Education, 120(2), 205-231. https://doi.org/10.1086/674370

Devos, G., Vanblaere, B., \& Bellemans, L. (2018). Stress en welbevinden bij schoolleiders: Een analyse van bepalende factoren en van vereiste randvoorwaarden [Stress and wellbeing of school leaders: an analysis of determinants and preconditions].

Flemish Ministry for Education and Formation. (2017). Statistical Year Book for Flemish Education 2016-2017. 2017. https://onderwijs.vlaanderen.be/nl/statistisch-jaarboek-van-hetvlaams-onderwijs-2016-2017-0

Forde, C. (2011). International Handbook of Leadership for Learning. 355-374. https://doi.org/10.1007/978-94-007-1350-5

Frost, D. (2008). “Teacher leadership": Values and voice. School Leadership and Management, 28(4), 337-352. https://doi.org/10.1080/13632430802292258

Hallinger, P. (2003). Leading Educational Change: reflections on the practice of instructional and transformational leadership. Cambridge Journal of Education, 33(3), 329-352. https://doi.org/10.1080/0305764032000122005

Hallinger, P., \& Heck, R. H. (2010). Leadership for Learning: Does Collaborative Leadership Make a Difference in School Improvement? Educational Management Administration \& Leadership, 38(6), 654-678. https://doi.org/10.1177/1741143210379060 
Hallinger, P., \& Murphy, J. (1985). Assessing the Instructional Management Behavior of Principals. The Elementary School Journal, 86(2), 217-247. https://doi.org/10.1086/461445

Harris, A. (2013). Distributed Leadership: Friend or Foe? Educational Management Administration and Leadership, 41(5), 545-554. https://doi.org/10.1177/1741143213497635

Harris, A., \& DeFlaminis, J. (2016). Distributed leadership in practice: Evidence, misconceptions and possibilities. Management in Education, 30(4), 141-146. https://doi.org/10.1177/0892020616656734

Hulpia, H., Devos, G., \& Rosseel, Y. (2009). Development and Validation of Scores on the Distributed Leadership Inventory. Educational and Psychological Measurement, 69(6), 1013-1034. https://doi.org/10.1111/j.1540-5915.1996.tb00842.x

Hulpia, H., Devos, G., \& Van Keer, H. (2011). The Relation Between School Leadership From a Distributed Perspective and Teachers' Organizational Commitment. Educational Administration Quarterly, 47(5), 728-771. https://doi.org/10.1177/0013161X11402065

Lavrijsen, J., \& Nicaise, I. (2016). Educational tracking, inequality and performance: New evidence from a differences-in-differences technique. Research in Comparative and International Education, 11(3), 334-349. https://doi.org/10.1177/1745499916664818.

Leithwood, K., Day, C., Sammons, P., Harris, A., \& Hopkins, D. (2006). Seven Strong Claims About Successful School Leadership. National College for School Leadership.

Leithwood, K., Harris, A., \& Hopkins, D. (2008). Seven strong claims about successful school leadership. School Leadership and Management, 28(1), 27-42. https://doi.org/10.1080/13632430701800060 
Leithwood, K., \& Jantzi, D. (2000). The effects of transformational leadership on organizational conditions and student engagement with school. Journal of Educational Administration Quarterly, 38(2), 112-129. https://doi.org/https://doi.org/10.1108/09578230010320064

Leithwood, K., Jantzi, D., \& Steinbach, R. (1999). Changing leadership for changing times. Open University Press.

Leithwood, K., Mascall, B., Strauss, T., Sacks, R., Memon, N., \& Yashkina, A. (2008).

Distributing leadership to make schools smarter: Taking the ego out of the system.

Leadership and Policy in Schools, 6(1), 37-67. https://doi.org/10.1080/15700760601091267

MacBeath, J., \& Dempster, N. (2009). Connecting Leadership and Learning (J. MacBeath \& N. Dempster (eds.)). Routledge. https://doi.org/10.4324/9780203894644

MacBeath, J., Dempster, N., Frost, D., Johnson, G., \& Swaffield, S. (2018). Strengthening the connections between leadership and learning: Challenges to policy, school and classroom practice. Routledge. https://doi.org/10.4324/9781351165327

MacBeath, J., O’Brien, J., \& Gronn, P. (2012). Drowning or waving? Coping strategies among Scottish head teachers. School Leadership and Management, 32(5), 421-437. https://doi.org/10.1080/13632434.2012.739870

MacBeath, J., Swaffield, S., \& Frost, D. (2009). Principled narrative. International Journal of Leadership in Education, 12(3), 223-237. https://doi.org/10.1080/13603120802684548

Marks, H. M., \& Printy, S. M. (2003). Principal Leadership and School Performance: An Integration of Transformational and Instructional Leadership. Educational Administration Quarterly, 39(3), 370-397. https://doi.org/10.1177/0013161X03253412 
Marsh, S. (2015). A Model for Leadership That Improves Learning: New Insights for Schools and Scholars. Leadership and Policy in Schools, 14(1), 67-103. https://doi.org/10.1080/15700763.2014.983132

Moens, B. (2019, September 5). Lerarentekort is de olifant in de kamer. De Tijd.

Muijs, D., \& Harris, A. (2006). Teacher led school improvement: Teacher leadership in the UK. Teaching and Teacher Education, 22(8), 961-972. https://doi.org/10.1016/j.tate.2006.04.010

Murphy, J., Elliott, S. N., Goldring, E., \& Porter, A. C. (2007). Leadership for learning: A research-based model and taxonomy of behaviors. School Leadership and Management, 27(2), 179-201. https://doi.org/10.1080/13632430701237420

Park, V., \& Datnow, A. (2009). Co-constructing distributed leadership: district and school connections in data-driven decision- making. School Leadership \& Management, 29(5), 477-494. https://doi.org/10.1080/13632430903162541

Penninckx, M., Vanhoof, J., De Maeyer, S., \& Van Petegem, P. (2016). Effects and side effects of Flemish school inspection. Educational Management Administration and Leadership, 44(5), 728-744. https://doi.org/10.1177/1741143215570305

Robinson, V. M. J., Lloyd, C. A., \& Rowe, K. J. (2008). The Impact of Leadership on Student Outcomes: An Analysis of the Differential Effects of Leadership Types. Educational Administration Quarterly, 44(5), 635-674. https://doi.org/10.1177/0013161X08321509

Sackney, L., \& Mitchell, C. (2008). Leadership for Learning: A Canadian Perspective. In J. MacBeath \& Y. C. Cheng (Eds.), Leadership for Learning: International Perspectives (pp. 123-136). Sense Publishers. 
Schelfhout, W. (2017). Toward Data for Development: A Model on Learning Communities as a Platform for Growing Data Use. In J. Vanthienen \& K. De Witte (Eds.), Data Analytics Applications in Education (pp. 37-82). Taylor \& Francis Group.

Sels, L., Vansteenkiste, S., \& Knipprath, H. (2017). Toekomstverkenningen arbeidsmarkt 2050 (Werk.Rapport 2017 nr.1) (Issue 1). Steunpunt Werk \& HIVA - KU Leuven.

Seltzer, J., \& Bass, B. M. (1990). Transformational Leadership: Beyond Initiation and Consideration. Journal of Management, 16(4), 693-703. https://doi.org/https://doi.org/10.1177/014920639001600403

Spillane, J. P., Harris, A., Jones, M., \& Mertz, K. (2015). Opportunities and challenges for taking a distributed perspective: Novice school principals' emerging sense of their new position. British Educational Research Journal, 41(6), 1068-1085. https://doi.org/10.1002/berj.3166

Torrance, D. (2013). Distributed leadership: Challenging five generally held assumptions. School Leadership and Management, 33(4), 354-372. https://doi.org/10.1080/13632434.2013.813463

Townsend, T., Acker-Hocevar, M., Ballenger, J., \& Place, A. W. (2013). Voices From the Field: What Have We Learned About Instructional Leadership? Leadership and Policy in Schools, 12(1), 60-88. https://doi.org/10.1080/15700763.2013.766349

Vanblaere, B., \& Devos, G. (2016). Relating school leadership to perceived professional learning community characteristics: A multilevel analysis. Teaching and Teacher Education, 57, 2638. https://doi.org/10.1016/j.tate.2016.03.003

York-Barr, J., \& Duke, K. (2004). What Do We Know About Teacher Leadership? Findings From Two Decades of Scholarship. Review of Educational Research, 74(3), 255-316. https://doi.org/10.3102/00346543074003255 
Page | 36 


\section{Table 1}

Principal respondent characteristics $(n=19)$ compared to the overall Flemish SE percentages.

\begin{tabular}{|c|c|c|c|}
\hline \multirow[t]{2}{*}{ Characteristic } & \multicolumn{2}{|c|}{ Interview } & \multirow{2}{*}{$\frac{\text { Flanders }}{\%}$} \\
\hline & $n$ & $\%$ & \\
\hline \multicolumn{4}{|l|}{ Gender } \\
\hline Female & 7 & 37 & 40 \\
\hline Male & 12 & 63 & 60 \\
\hline \multicolumn{4}{|l|}{ Age } \\
\hline$<35$ years & 2 & 11 & 3 \\
\hline $35-44$ years & 6 & 32 & 21 \\
\hline $45-54$ years & 6 & 32 & 37 \\
\hline$>54$ years & 5 & 26 & 39 \\
\hline \multicolumn{4}{|l|}{ Years of experience } \\
\hline$<3$ years & 3 & 16 & $\mathrm{n} / \mathrm{a}$ \\
\hline $3-10$ years & 5 & 26 & $\mathrm{n} / \mathrm{a}$ \\
\hline$>10$ years & 11 & 58 & $\mathrm{n} / \mathrm{a}$ \\
\hline \multicolumn{4}{|l|}{ School size (\# pupils) } \\
\hline Small $(<300)$ & 3 & 16 & 37 \\
\hline Medium (300 - 900) & 9 & 47 & 56 \\
\hline Large (> 900) & 7 & 37 & 7 \\
\hline \multicolumn{4}{|l|}{ Educational Network } \\
\hline GO! & 2 & 11 & 23 \\
\hline POV & 3 & 16 & 3 \\
\hline OVSG & 3 & 16 & 4 \\
\hline $\mathrm{KOV}$ & 11 & 58 & 69 \\
\hline Other & 0 & 0 & 1 \\
\hline \multicolumn{4}{|l|}{ Location } \\
\hline Urban & 11 & 58 & 39 \\
\hline Semi-urban or rural & 8 & 42 & 61 \\
\hline
\end{tabular}

Source. Flemish Ministry for Education and Formation (2017). 


\section{Table 2}

Flemish SE school leaders' activity span based on Murphy et al.'s (2007) LFL activity framework $(n=19)$.

\begin{tabular}{lcc}
\hline Description & \multicolumn{2}{c}{ Dimension } \\
\cline { 2 - 3 } & References & Sources \\
\hline Vision for learning & 10 & 8 \\
Instructional programme & 33 & 18 \\
Curriculum programme & 0 & 0 \\
Assessment programme & 6 & 2 \\
Communities of learning & 25 & 14 \\
Resource acquisition and use & 9 & 6 \\
Organizational culture & 8 & 5 \\
Social advocacy & 18 & 13 \\
Administering and running an organisation & 30 & 17 \\
$\quad$ Interpersonal relations and welfare & 5 & 5 \\
$\quad$ Preparation of large projects & 8 & 8 \\
Organizing, planning and informing & 6 & 6 \\
Administration and IT coordination & 11 & 7 \\
\hline
\end{tabular}

Note. 'Source' indicates every unique respondent within the sample. 'Reference' indicates every unique reference made to an element within the (sub)dimensions across sources. 


\section{Table 3}

Leadership in Flemish secondary education based on school leaders' and innovation coaches' accounts of reality and personal preference $(n=22)$.

\begin{tabular}{lcccc}
\hline Description & \multicolumn{2}{c}{ Sub dimension } & \multicolumn{2}{c}{ Dimension } \\
\cline { 2 - 5 } & References & Sources & References & Sources \\
\hline Transformational leadership & 24 & 17 & & \\
$\quad$ Vision building & 15 & 12 & 64 & 21 \\
$\quad$ Intellectual stimulation & 19 & 12 & & \\
$\quad$ Individual consideration & 6 & 5 & & \\
$\quad$ Idealized influence & & & & \\
Instructional leadership & 6 & 5 & 26 & \\
$\quad$ Defining the school's mission and vision & 5 & 5 & & \\
$\quad$ Managing the instructional program & 15 & 13 & & \\
$\quad$ Promoting the school's learning culture & & & & \\
Distributed leadership & 18 & 10 & & \\
$\quad$ Delegation and dispersion of responsibilities & 10 & 8 & & \\
Broad participation and regular consultation & 6 & 5 & 44 & \\
Facilitation of cooperation & 8 & 7 & & \\
Culture & 2 & 2 & & \\
$\quad$ Professional development & & &
\end{tabular}




\section{Table 4}

References to leadership for learning in Flemish secondary education based on school leaders' and innovation coaches' accounts of reality and personal preference $(n=22)$ sorted according to the nature of the comment.

\begin{tabular}{lcccccccccc}
\hline LFL principles for practice & \multicolumn{1}{c}{ Reference type } & & \\
\cline { 2 - 8 } & + & + & - & - & $*$ & $*$ & Total & Total \\
& $(\mathrm{R})$ & $(\mathrm{S})$ & $(\mathrm{R})$ & $(\mathrm{S})$ & $(\mathrm{R})$ & $(\mathrm{S})$ & $(\mathrm{R})$ & $(\mathrm{S})$ \\
\hline 1. Maintaining a focus on learning & 23 & 11 & 6 & 5 & 2 & 2 & 31 & 14 \\
2. Creating conditions favorable to learning & 28 & 17 & 0 & 0 & 2 & 2 & 30 & 18 \\
3. Dialogue about leadership and learning & 15 & 12 & 0 & 0 & 5 & 3 & 20 & 12 \\
4. Sharing leadership & 23 & 11 & 7 & 5 & 12 & 8 & 42 & 20 \\
5. Sharing accountability & 14 & 9 & 1 & 1 & 4 & 4 & 19 & 13 \\
\hline
\end{tabular}

Note. 'S' refers to 'sources' whilst ' $R$ ' refers to 'references'. $A$ ' + ' indicates all comments that perfectly aligned with the descriptions about LFL as provided by the Carpe Vitam study. A '- 'indicates all comments that were opposite to the aforementioned descriptions of LFL. $A$ '*' indicates all comments that added a critical reflection to one or more of LFLs five principles for practice. 


\section{Appendix 1}

Coding scheme for leadership styles

\begin{tabular}{|c|c|c|}
\hline Category & Indicators & Exemplary quotations \\
\hline $\begin{array}{l}\text { Transformational } \\
\text { leadership }\end{array}$ & $\begin{array}{ll}\text { - } & \text { Vision building } \\
\text { - } & \text { Intellectual stimulation } \\
\text { - } & \text { Individual consideration } \\
\text { - } & \text { Idealized influence }\end{array}$ & $\begin{array}{l}\text { "I think that being able to design a vision with a team is } \\
\text { fundamental. To take on leadership that creates a framework in } \\
\text { which people can work, excel and develop themselves." } \\
\text { (Innovation coach } 1 \text { - Male }-4 \text { years of coaching experience) } \\
\text { "[Effective school leadership] implies entering into a dialogue } \\
\text { with colleagues daily, to support and challenge them." } \\
\text { (Innovation coach } 2 \text { - Male }-2 \text { years of coaching experience) }\end{array}$ \\
\hline Instructional leadership & 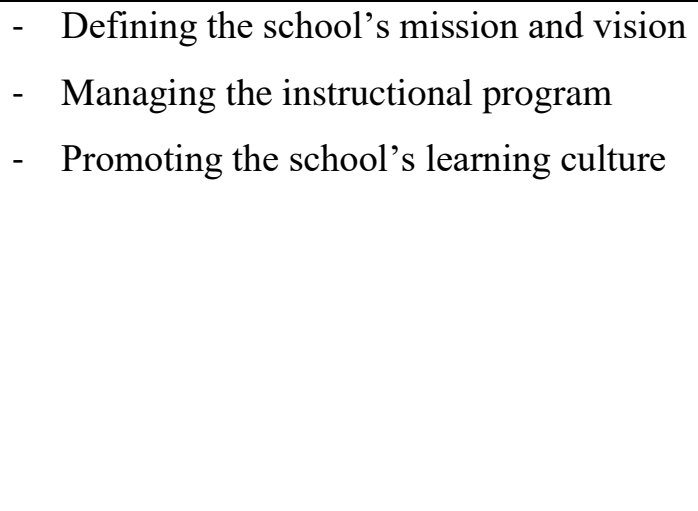 & $\begin{array}{l}\text { "On average, I think my personnel shows little initiative or is } \\
\text { little innovative. If I am honest: over the past twelve years, all } \\
\text { reforms happened top-down." (Principal } 19 \text { - Male - } 12 \text { years of } \\
\text { experience) } \\
\text { "[Dialogue with co-workers] mostly focusses on pupils. A pupil } \\
\text { has been sick, how is he doing now [in class]? It has to do with } \\
\text { department groups: what are they currently working on?" } \\
\text { (Principal } 18 \text { - Female - } 13 \text { years of experience) }\end{array}$ \\
\hline
\end{tabular}


Distributed leadership - Delegation and dispersion of responsibilities

- Broad participation and regular consultation

- Facilitation of cooperation

- Culture

- Professional development therein
"I always have the final responsibility. Often I am the one who gives input too but not always." (Principal 7 - Female - 10 years of experience)

"I strongly believe in participation and clarity about the degree of participation. So that people do not start to wonder whether they are here to decide, advise, ... That should be clear." (Principle 11 - Male -13 years of experience) 


\section{Appendix 2}

Coding scheme for Carpe Vitam's five principles for an LFL practice

\begin{tabular}{|c|c|c|}
\hline Category & Indicators & Exemplary quotations \\
\hline $\begin{array}{l}\text { Maintaining a focus on } \\
\text { learning }\end{array}$ & $\begin{array}{l}\text { - Allowing everyone within the school opportunities to } \\
\text { learn whilst recognizing that each of them learns in a } \\
\text { unique way bound up in a social, cultural and } \\
\text { emotional setting. } \\
\text { - Keeping an eye out for learning and fostering learning } \\
\text { - Activities or strategies that help avoid energy and } \\
\text { attention to be (too much or frequently) diverted to } \\
\text { other dimensions of schooling other than learning. }\end{array}$ & $\begin{array}{l}\text { "A lot of things that go awry in society, people try to solve } \\
\text { through education. Then you get ideas from ministers and their } \\
\text { cabinets: 'Isn't this something we tackle via schools?' Sometimes } \\
\text { that is an order, sometimes not. If it is not an order, you leave it at } \\
\text { that." (Principal } 4 \text { - Male - } 20 \text { years of experience) } \\
\text { "Within a school context you need to be informed about } \\
\text { didactical developments [...] You need to make sure to follow up } \\
\text { on those things: current affairs, trends, educational events. I think } \\
\text { that is a very important quality you should possess as a principal." } \\
\text { (Principal } 3 \text { - Male - } 12 \text { years of experience) }\end{array}$ \\
\hline $\begin{array}{l}\text { Creating conditions } \\
\text { favourable to learning }\end{array}$ & $\begin{array}{l}\text { - Ensuring and stimulating socially and physically safe } \\
\text { places for learning } \\
\text { - } \quad \text { Creating opportunities to reflect on the nature, skills } \\
\text { and processes of learning. } \\
\text { - } \quad \text { Encouraging risks and experiments. } \\
\text { - Valuing failures and successes equally. }\end{array}$ & $\begin{array}{l}\text { "For me, safety is a priority. If the government cannot guarantee } \\
\text { safety in schools than conclusions should be drawn. I consider it } \\
\text { absolutely wrong when a child goes to a school and that school is } \\
\text { unsafe." (Principal } 13 \text { - Male - } 14 \text { years of experience) } \\
\text { "We find ourselves in a GOK-system }{ }^{1} \text { from which we receive } 33 \\
\text { GOK-hours. We decided to divide these hours among quite a lot } \\
\text { of people, each receiving four hours, so that we got a team for } \\
\text { thinking together." (Principal } 9-\text { Female - } 12 \text { years of }\end{array}$ \\
\hline
\end{tabular}

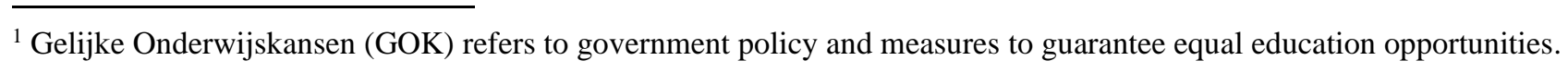


Engaging in a dialogue about leadership and learning
- LFL as a practice is made explicit, discussable (e.g., through collegial inquiry) and transferable.

- The link between leadership and learning is made a shared concern through dialogue about values, understandings and practices.

- Factors which inhibit and promote leadership and learning are examined and addressed.

- Consultation with 'critical friends' (e.g., fellow practitioners) strengthens the active and ongoing dialogue about leadership and learning.
"What I also find important, and try to do more often, is cooperating with colleges and universities. [...] We are in a project with [a Flemish University college] about the study load of our pupils. University college students help us develop things." (Principal 6-Male -8 years of experience)

"We have a pupil tracking system in which everyone can digitally add specific experiences on the learning and care of a pupil." (Innovation coach 2 - Male -2 years of coaching experience)
Sharing leadership
- Setting up and maintaining structures that support participation in developing the school as a learning community.

- Collaborative patterns of work and activity across boundaries of subject, role and status are promoted.

- Everyone is encouraged to take the lead.

- Sense of shared purpose, social and reciprocal support

- Sensitivity to voice

- Experience and expertise of staff, students and parents are drawn upon as resources.
"You should use parents and their network. We needed a new website and just asked parents: 'Is there anyone who wants to help us brainstorm over the course of two to three meetings?' Three professionals responded: 'We will help you out'." (Principal 18 - Female - 13 years of experience)

"With regard to policy in the past, you [as a principal] had to literally tell: 'This is how we will do it'. Now, [co-workers] come to you and tell: 'Maybe we should do things this or that way, because ...'. Then you can say: 'Great! That is something we'll do.'" (Principal 12 - Male - 10 years of experience) 
Sharing accountability

- Internal accountability through systematic self-

evaluation at classroom, school and community level.

- Strong internal support gives rise to a resilience and vitality that enables the school to tell its own story in its own register and in terms of its own values.

- National policies are recast in accordance with the school's core values.

- A focus on evidence.

- A focus on sustainability, succession and leaving a legacy.
"At Flemish level, they should consider setting up a talent pool for teachers who are willing and have the ambition to do something more than solely teaching throughout their careers. People you can already bring into a mind-set that says: '[...] this was how things were done in the past but today new principles of managing and leading organizations are tried'. We will need such people in future education." (Innovation coach 3 - Male - 4 years of coaching experience)

"Many principals do not dare to, but you should have yourself evaluated by your staff. [...] They can really tell what both your strengths and weaknesses are. For pupils as well. If only they could evaluate their teachers [...] then you [as a teacher] can [start to] focus on your talents." (Principal 3-Male - 12 years of experience) 